\title{
Factors Affecting the Employees Performance in University of Agriculture Faisalabad, Pakistan
}

\author{
Muhammad Usman Zafar ${ }^{1}$, Muhammad Asim², Muhammad Iqbal Zafar ${ }^{3}$ Nazia \\ Malik $^{2}$ and Kashif Shabbir Khan ${ }^{4}$ \\ ${ }^{I}$ Lecturer, Department of Business Administration, G.C University Faisalabad, Pakistan \\ ${ }^{2}$ Department of Sociology, G.C University Faisalabad, Pakistan \\ ${ }^{3}$ Dean, Facility of Social Sciences, University of Agriculture Faisalabad, Pakistan \\ ${ }^{4}$ Department of Business Administration National University of Modern Languages (NUML) Islamabad
}

\begin{abstract}
The work performance and efficiency of employees has a significant effect on any organization. The purpose of this research is to evaluate the factors that affect employee performance and to identify factors which influence the employees work performance in university of Agriculture Faisalabad, Pakistan. Employees are the most valuable asset in any organization. A successful and highly productive performance can be achieved by engaging the employee in improving their performance. The sample of the study was 75 respondents who were employed in Agriculture University, Pakistan. It is found that better education, higher salary; facilities at work place communication of the employees with their seniors were highly associated with batter job performance. Impact of family background, type of family and marital status had not linkages with job performance.
\end{abstract}

Key words: employee's performance, organization, and job satisfaction

\section{Introduction}

Job satisfaction describes how contented an individual is, with his or her job. There is a variety of factors that can influence a person's level of job satisfaction; some of these factors include the level of pay and benefits, the quality of the working conditions, leadership and social relationships, and the job itself (Amable, 2007). Employee performance is defined as the record of outcomes achieved, for each job function, during a specified period of time. When viewed this way, performance is represented as a distribution of outcomes achieved, and performance is measured using a variety of parameters that describe an employee's pattern of performance over time. By explicitly distinguishing between performance variations due to extraneous (system) constraints and variations that are under the employee's control, this method provides meaningful information on how to manage and improve employee performance(Kane, 1982). (Susan, 2007) defined that performance management is the process of creating a work environment or setting in which people are enabled to perform to the best of their abilities. Performance management is a whole work system that begins when a job is defined as needed.

In Pakistan labor force include all persons who are of ten years and above, and during the period are without work, currently available for work and seeking for work. On the basis of the existing population of 164.00 millions with labor force participation rate of 27.46 percent, the total labor force comes to 39.24 million. Employees labor force is 38 percent According to this about 2.4 million persons of labor force were estimated as unemployed in 2008 (World Fact Book, 2008).

There are at present 49 General Universities in the Public sector, 36 Universities in the private sector, 8 degree awarding institutes in the private sector and 18 degree awarding institutes in the private sector (GOP, 2005). Keeping in view the growing number of universities in Pakistan, it is essentially important to address the issue of employees work performance. Without enhancing their performance, the goals of quality education and research seem impossible. There must be a conscious attempt made to bring the expectations of the literate labor force which is either not in employment or likely to come into the labor force in the future, into line with actual possibilities in the job market. This should be done both at an educational level as well as at the level of training programs for improving their performance at the work place. This study is particularly designed to identify factors which affect the employees work performance in the individual and institutional context.

\section{Methodology}

The present study is conducted in University of Agriculture, Faisalabad to identify factors affecting employees' performance within individual and institutional context. In the university there are six faculties and one division -Faculty of Science, Faculty of Agricultural Economics and Rural Sociology, Faculty of Agriculture, Faculty of Agricultural Engineering, Faculty of DVM and Faculty of Animal Husbandry and Division of Education and Extension. The teaching and administrative staff of the university was eligible 
respondents. The sample consisted of 75 professors, Associate professors, Assistant Professors, Lecturers/Research Officers and administrative Staff. Systematic random sampling was used for the selection of the respondents. Chi square and gamma test were applied for test the strengthen of relationship and direction of the dependent and independent variables.

\section{Results And Discussions}

In this section findings of descriptive i.e. frequency distribution and inferential analysis -application different statistical tests such as Chi-square, Gama, Spearman, Pearson's Correlations tests are discussed. Descriptive analysis is employed to describe the information relating to job performance while the inferential analysis is carried out to examine the relationship between predicting and response variables. In table 1 indicates information about the distribution of gender. The sex of the respondents is an important aspect affecting attitude. It has been generally observed that males are more rational and logical in their thinking than females. The table shows that 84.0 percent of the respondents were males, while remaining 16.0 percent the respondents were females. This proportion of males and females in economic activities is reflections of general society. Pakistan is male dominant society where females' participation in economic activities is not respected and valued. In order to examine the association between gender and employee's performance, inferential analysis is carried out. The values of chi- square and gamma 6.98 and .498 significant at 5 percent level of different statistical tests such Chi-square; reflect that sex of an employee does affect the job performance. Males were more efficient than females in performing work responsibilities. Different other studies also have similar findings. In developing societies like Pakistan females find it difficult to spare more or extra time after office hours to remain in office to perform office responsibilities.

In the present research, age was considered as the number of complete years lived by the respondents at the time of interview. It was clearly based upon the respondents' own reply. Age of respondents is an important indicator of job performance. It is generally viewed that younger people are more eager, energetic and enthusiastic in performing their responsibilities than the older. Keeping in view this aspect, information on current age of the respondents are gathered given in table 4.2.1. Table indicates that majority of the respondents $(40 \%)$ were in the age group of 30-40 years, followed by the respondents of age category 20-30 years and their percentage was 33.3. The remaining respondents were 18.7 and 8 percent of age group 41-50 and above 50 years respectively. Education is considered to be very important sociological indicator of the respondent's behavior as it is a method of influencing the human behaviour. For the percent study, the level of the education was determined by the number of years completed by the respondent in the educational institutions.

Education means how many years or level of formal education have completed by the respondents. Education is an important social indicator and it affects human behavior and attitudes in understanding the different phenomenon. It is generally perceived that people with better education likely to perform well as compared to people with poor level of education. The people with high level of education can properly organize their different activities what they have to perform. The information on the respondents' education level was collected. Table indicates that respondents had different level of education from Matric to Post-doctorate level. The percentage of the respondents i.e. 49.4\% had M.Sc/ M.Sc (Hon) level of education. The second high percentage of respondents had Ph.D. degrees, their percentage was $16 \%$. The higher percentage of $2^{\text {nd }}$ category was due to reasons that study is conducted in university of agriculture, Faisalabad and minimum qualification for recruitment is Master. The percentage of the respondents who had 10 grade, 12 grade and 14 grade were 5.3, 13.3, 10.7 percent respectively. Different statistical tests were applied to examine relationship between qualification and job performance as it hypothesized that person with better qualification likely to perform well at work place than a person with low educational attainment. Table 2 clearly reflects the effect of qualifications on job performance as the values of Chi-square (23.66) at 5 percent level. The positive value of Gama which is 0.595 significant at one percent level of significance reflects that education or qualification is directly associated with job performance.

Table 1: Socio economic and demographic characteristics of the respondents

\begin{tabular}{|l|c|c|}
\hline Gender & Frequency & Percentage \\
\hline Male & 63 & 84.0 \\
\hline Female & 12 & 16.0 \\
\hline Age categories & & \\
\hline $20-30$ & 25 & 33.3 \\
\hline $31-40$ & 30 & 40.0 \\
\hline $41-50$ & 14 & 18.7 \\
\hline Above 50 & 6 & 8.0 \\
\hline Qualification & & \\
\hline 10 grade & 4 & 5.3 \\
\hline
\end{tabular}




\begin{tabular}{|l|c|c|}
\hline 12 grade & 10 & 13.3 \\
\hline 14 grade & 8 & 10.7 \\
\hline Master & 37 & 49.4 \\
\hline Ph.D and above & 16 & 21.3 \\
\hline Family background & 41 & 54.7 \\
\hline Urban & 34 & 45.3 \\
\hline Rural & & \\
\hline Family type & 25 & 33.3 \\
\hline Nuclear & 50 & 67.7 \\
\hline Joint/Extended & & \\
\hline Marital status & 60 & 80.0 \\
\hline Married & 14 & 18.7 \\
\hline Un-married & 1 & 1.3 \\
\hline Divorced & & \\
\hline Occupational Status & 10 & 7.5 \\
\hline Administrative Staff & 38 & 67.5 \\
\hline Lecturer/Research & & 10.7 \\
Officer & 15 & 9.3 \\
\hline Assistant Professor & 7 & 8.0 \\
\hline Associate Professor & 2 & \\
\hline Professor & & 28.0 \\
\hline Salary (Rs.) & 21 & 32.0 \\
\hline Up to 10000 & 24 & 24.0 \\
\hline 10001-20000 & 18 & 16.0 \\
\hline 20001-40000 & 12 & \\
\hline Above 40000 & & \\
\hline
\end{tabular}

Family background weather the respondents belonged to rural area or urban area is a factor $\mathrm{n}$ relation to performance of respondents. It is viewed that people with rural background like to have strict attitude and take more time to change than people who have urban background. The urban people are exposed to different types of media such as printed, electronic etc. Table indicates that 54.7 of the employees belonged to urban area while 45.3 had their rural background. Different statistical tests along with Gama and pearsons correlation values do not support the relationship between background of the respondents and job performance. It reflects that whether the respondents belong to rural area or urban, it makes no difference in their job performance.

Family structure means whether a person lives nuclear or joint family system. The family structure is the reflection of the environment and develops interaction of family members. The interaction of family members does influence their behavior in performing economic activities. That's why information on family structure was gathered. The information given in table indicates that 33.3 percent of the respondents were lived in nuclear family setup while majority of the respondents that is 67.7 percent had joint family arrangement. It reflects that although change from collectivism to individuals is occurring but slowly. It emerges that still the traditional values were dominated. In order to examine the association between the family type and employee's performance, inferential analysis is carried out. The values 8.993 Chi-square, showed a week relationship between type of family of respondents and job performance. These statistics lead to conclusion that job performance is not greatly influenced by the type of family of the respondents. Gamma test and Pearson's Correlation analysis is carried out to see the direction and strength of relationship between family structure and job performance. Both values also show no significant relationship between the variables.

In this study marital status has 4 categories married, un-married, divorced and widow. These aspects of the person do influence their attitude to perform different activities of life - social activities, economic activities, political or culture activities. The variable has its significance in determined the performance of person. It is viewed that married people likely to perform well their economic activities than un-married and others, particularly divorced and widow. Divorced and widowhood are the bitter aspects in our society. These people perform their responsibilities of life half heartedly. In this study information in table viewed that 80.0 percent of the respondents were married while 18.7 percent were un- married respondents, there was just one respondent who was divorced status. In order to examine association between marital status and employee's performance, inferential analysis is carried out. The values 5.190 of Chi-square showed a non significant relationship between marital status of respondents and job performance. These statistics leads to the conclusion that job performance is not influenced by the marital status of the respondents. Gamma test and Pearson's Correlation analysis also do not support this relationship. 
Table 2: Bi-variate analysis for showing relationship between socio economic, demographic characteristics and job performance

\begin{tabular}{|l|c|c|c|c|}
\hline \multicolumn{1}{|c|}{ Variables } & $\begin{array}{c}\text { Pearson Chi- } \\
\text { Square value }\end{array}$ & Gamma value & $\begin{array}{c}\text { Degree of } \\
\text { Freedom }\end{array}$ & $\begin{array}{c}\text { Asymp. Sig. (2- } \\
\text { sided) }\end{array}$ \\
\hline Gender & 6.982 & .498 & 2 & .030 \\
\hline Qualification & 23.66 & .595 & 12 & .023 \\
\hline Family Background & .812 & -1.97 & 2 & .666 \\
\hline Family type & 8.993 & .253 & 4 & .061 \\
\hline Marital status & 5.190 & .390 & 4 & .268 \\
\hline Occupational Status & 16.602 & .331 & 8 & .035 \\
\hline
\end{tabular}

Occupation is an important indicator of social status or social standing of a person in a society. Some professionals are considered respectable while some not. The people with better professional are valued by society and they perform well than that people who have not batter professions. The table 1 indicates that 75.0 percent of the respondents were administrative staff, and lectures/ research officers. 10.7, 9.3, 8.0 percent of the respondents were Assistant Professor, Associate Professor, Professors respectively. Different statistical tests were applied to examine relationship between occupation and job performance as it hypothesized that person with better occupation likely to perform well at work place than a person with lower occupational status. Table 2 clearly reflects the effect of occupation on job performance as the values of Chi-square (16.602), significant at 5 percent level. Gamma test and Pearson's Correlation analysis is carried out to see the direction and strength of relationship between occupation and job performance. The hypothesis that there is direct relationship between occupation and job performance is established. The findings indicate that higher is occupational status of an employee better will be work performance at work place. The occupation affects human satisfaction, job commitment and job loyalty which are necessary elements for job performance. Salary is a reflection of economic condition of employees and it does affect the attitude to perform their duty at work place. Respondents with have better salary likely to perform well than employees have poor salary. Table 1 indicates that 28.0, 32.0, 24.0 and 16.0 of the employees had salary in the range up to Rs10,000,10001 to 20000, 20001 to 40000 and plus 40000 respectively.

Table 3: Distribution of the respondents about organizational environment and job performance

\begin{tabular}{|l|c|c|c|c|c|c|}
\hline \multirow{2}{*}{ Attitudinal statements } & \multicolumn{2}{|c|}{ To great extent } & \multicolumn{2}{c|}{ To some extent } & \multicolumn{2}{c|}{ Not at all } \\
\cline { 2 - 7 } & Freq. & \%age & Freq. & \%age & Freq. & \%age \\
\hline Feel Stress & 21 & 28.0 & 45 & 60.0 & 9 & 12.0 \\
\hline Facilities available & 26 & 34.7 & 48 & 64.0 & 1 & 1.3 \\
\hline Level of communication and Job Performance & 54 & 72 & 19 & 25.3 & 2 & 2.7 \\
\hline Satisfy with performance and Job performance & 48 & 64.0 & 27 & 36.0 & - & - \\
\hline
\end{tabular}

Stress is an important indicator in determining the performance of an employee in an organization or in institution. Stress is categories as negative or positive. The positive stress of employees links with better employee's performance and management at work place, resulting higher productively. On the other hand the negative stress adversely affects the work performance of the employees. The negative stress creates unconducive and threading environment at work place. In this environment the employees finds ways and means to remain away at work place and avoid interacting with their seniors. This attitude of employees resulted in poor performance. Likert scale with three categories - to a great extent, to some extent and not at all is used to measure the stress level at work place. $28 \%$ of the respondents viewed that they feel stress to a great extent, while $60 \%$ of the respondents had stress to some extent. There were small percentage of the respondents (with in $12 \%$ ) who reported no stress at the work place. The findings on stress provide insight about the environment in university. The high percentage of the respondents who felt stress could not perform their responsibilities with interest and devotion; surely there are adverse implications in achieving the organization goals-quality of research and teaching and effective management. In order to observe the association between the feeling of stress and employee's performance, inferential analysis is carried out. The values of chi square (19.465), showed a significant relationship between feeling of stress and job performance at one percent level of confidence. In order to observe the association between the feeling of stress and employee's performance, inferential analysis is carried out. Gamma test is also carried out to see the direction and strength of relationship between feeling of stress and job performance. The negative values of Gamma -.654 which are significant at one percent level of significance, reflect that variable feeling of stress is inversely associated with job performance. The hypothesis that there is indirect relationship between feeling of stress and job performance is established. The findings indicate that higher is the feeling of stress of an employee lesser will be the work performance at work place. The feeling of stress has negative influence on the performance. These statistics leads to the conclusion that job 
performance is influenced by feeling of stress of the respondents. These statistics leads to the conclusion that job performance is influenced by feeling of stress of the respondents.

The office with better facilities in terms of furniture, computer facilities, air conditioner, administrative staff etc. depending upon the nature of office contributes towards work performance of employees in an organization. It is observed that if offices are equipped with better facilities then employees perform their duties with interest, dedication, devolution and vice-versa. In this study employees were asked about the facility available to them to perform their office duties and responsibilities. Information given in table 3 indicates that more than one third $34.7 \%$ had better facilities to great extent in their offices. There was a huge majority that is i.e. $64 \%$ of the respondents who reported that facilities available to them can be categories to some extend reflecting that they were not fully satisfied with the facilities available to them in their offices. There was just one respondent who reported in not at all indicting no facility was available to him/her to perform the office responsibilities. In order to observe the association between the facilities available and employee's performance, inferential analysis is carried out. The values of chi square (18.574) showed a significant relationship between facilities available and job performance at one percent level of confidence. These statistics lead to suggest that job performance is influenced by facilities available to employees at their work place. Gamma test and Pearson's Correlation analysis is carried out to see the direction and strength of relationship between facilities available and job performance. The positive value of Gamma 801which are significant at one percent level of significance, reflect that variable facilities available is directly associated with job performance. The hypothesis that there is direct relationship between facilities available and job performance is established. The findings indicate that higher the facilities available to employees greater will be the work performance at work place. The facilities available have positive influence on the performance of employees.

Table 4: Bi-variate analysis for showing relationship between organizational environment and job performance

\begin{tabular}{|l|c|c|c|c|}
\hline \multicolumn{1}{|c|}{ Statements } & $\begin{array}{c}\text { Pearson Chi-Square } \\
\text { value }\end{array}$ & Gamma value & $\begin{array}{c}\text { Degree of } \\
\text { Freedom }\end{array}$ & Asymp. Sig. (2-sided) \\
\hline Feel Stress & 19.465 & -.654 & 4 & .001 \\
\hline Facilities available & 18.574 & .801 & 4 & .001 \\
\hline $\begin{array}{l}\text { Level of communication } \\
\text { and Job Performance }\end{array}$ & 14.160 & .487 & 4 & .007 \\
\hline
\end{tabular}

Communication between the employees working at different levels of hierarchy does affect the performance of employees which ultimately link with achieving organizational goals. It has been viewed that better horizontal communication (among the employees of same cadres or level), and vertical communication (communication between the juniors and seniors) helps in creating and promoting the conducive environment at the work place. The conducive environment is essentially important rather a pre-condition for employees to improve work performance. It is reported that the employees who have better communication with their fellows or same cadres and with seniors they perform well at work place. The Information given in table 3 on the issue indicates that $72 \%$ of respondents expressed that they had good communication with their seniors. They can express without hesitation with the seniors. $25.3 \%$ of the respondents reported about level of communication with superiors, is just ok (normal) reflecting dissatisfaction of their communication with seniors. The remaining $2.7 \%$ of the respondents had given answer in not at all. Muhammad and Memon, (2012) found that majority of employees said that they have no participation or occasional participation in decision making and communication. Only few respondents said that management involves them in the major decision making process, including decisions related to their jobs. The values of chi square 14.160 showed a significant relationship between level of communication and job performance at one percent level of significance. These statistics lead to conclude that job performance is associated with level of communication of junior and senior employees. Gamma test is also carried out to see the direction and strength of relationship between level of communication and job performance. The positive values of Gamma.487 which is significant at one percent level of significance, reflect that variable level of communication is directly associated with job performance. The hypothesis that there is direct relationship between level of communication and job performance is established. The findings indicate that higher the level of communication of an employee greater will be the work performance at work place. The level of communication has positive influence on the performance of employees. The ultimate objective of research was to examine the level of satisfaction of university employee's performance and to identify the factors affecting the employees work performance. It was asked from respondents to what extent they are satisfied with their work performance. $64 \%$ of respondents reported that they are satisfied with their work performance to a great extent, while $36 \%$ of respondents were satisfied to some extent with their work performance. In other words majority of respondents work performance can be categorized as good, while the performance of others cannot be considered as good. 


\section{Relationship Established}

- Males had better performance than females.

- Respondents with better education had better job performance than the respondents with low level of education.

- The respondents had with better salary had better performance than the respondents with low salary. Respondents who were satisfied with their salary performed well than those who were not satisfied with their salary.

- Performance of duty with responsibility is associated with job performance. The respondents who performed their duty responsibly had better performance than the respondents who performed the duty without caring their responsibility.

- The employees who had better facility had better performance than the employees who had poor/insufficient facilities.

- The level of communication of the employees with their seniors is associated with job performance. The employees who had better communication with their seniors performed well than the employees who had low/poor level of communication.

\section{Relationship Not Established}

- Family background whether the respondents belonged to rural or urban area had no link with job performance. Both backgrounds have no role in job performance.

- Family arrangement whether the respondents had nuclear or joint structure has no relationship with job performance.

- Marital status is not associated with job performance. Married or un-married was equal in job performance.

\section{Conclusion}

Descriptive and inferential analysis demonstrate that institutional factors are more importance like salary, technical training, responsibility in performing duties, disciplined environment, stress level at work place, level of communication and understanding between the juniors and seniors employees, facility available at work place than individual factors like family status, family background, marital status, occupational and religious attachment.

\section{Suggestion}

Training is an essential component for improving employees performance, it is suggested that short and long term training programs should be arranged to enhance technical skills and technical knowledge to accomplish job requirements. Appropriate salary addresses economic needs of employees. It is essentially importance to enhance their salary keeping in view their performance and technical knowledge. There is a need to create an environment in which employees can organize themselves and perform their duty with responsibility and contribute toward achieving organization goals. Punctuality and regularity in observing office hours is key element to enhance job performance. Necessary administration steps are required ensure employees regularity and punctuality. Stress on employees at work place does adversely affect employees' ability to perform. Necessary steps should be taken to create conducive environment in which employees can excel according to their potential. Coordination and communication between the seniors and juniors employees of the institution are key elements to improve job performance, so there is a need to create an environment of confidence and trust in which juniors or subordinates employees can communicate and interact with the seniors without hesitation and fear. Without providing better facility, better performance from their employees cannot be expected. It is vitally importance to equip the classrooms with audio-visual facility, offices with computers, and internet and laboratories with required instruments/apparatus.

\section{Reference}

[1] Amable, B., L. Demmou and D. Gatti. 2007. Employment Performance and Institutions: New Answers to an Old Question. Discussion Paper No. 2731, Germany. Retrieved From. http://ftp.iza.org/dp2731.pdf

[2] GOP. 2005. Government of Pakistan. Economic Survey 2004-05, Ministry of Finance, Islamabad.

[3] Kane, J.S. 1982. Rethinking the problem of measuring performance: Some new conclusions and a new appraisal method to fit them. Paper presented at the Fourth Johns Hopkins University National Symposium on Educational Research, Washington, DC.

[4] Muhammad, G. and U.Memon. 2012. Determinants of Employee Motivation - A Case Study of Afroze Textile Industries Limited, Karachi, Pakistan. IOSR Journal of Business and Management. 4 (3): 22-25

[5] Susan M. 2007. Human Resources. American Society for Quality's Journal for Quality and Participation.

[6] World Fact Book, 2008. Central Intelligence Agency, Islamabad, Pakistan. 